\title{
EDITORIAL
}

\section{KEEPING THE ALIENS OUT}

$\mathrm{T}$ his year the SCAR lecture to the XXXV ATCM in Hobart was given by Alek Terauds on the results from the IPY project on non-native introductions. It was a timely reminder both of the success of the recent work on characterizing routes for introductions and of the complexities of controlling the arrival of new species in Antarctica from so many countries. On the continent itself there is, as yet, little evidence that new species are rapidly appearing but in the Maritime Antarctic islands problems are already emerging and should cause concerns now.

A paper in Antarctic Science has already documented the spread of Poa annua from around Arctowski Station to recently deglaciated areas some distance away, with no apparent attempt by the Polish Programme to eradicate the grass at source. Now there is evidence of Juncus bufonius in the soil seed bank on the same island, whilst another recent paper has documented the increased risk of transporting propagules to Syowa from the new cargo handling area in Tokyo. To add to this there was a report in Hobart of a tourist scattering barley seeds at Telefon Bay on Deception Island and recent studies on imported fresh food that demonstrated just what a diverse group of aliens they can bring into the area. The catalogue of disasters on the sub-Antarctic islands demonstrates how many of the aggressive introduced plants have ousted native species from some niches, overgrazing by introduced herbivores has changed the diversity of native plant communities and introduced rats, mice and invertebrates are successfully preying on native species.

A second field needs to be considered alongside this - the potential for the accidental introduction of diseases. The Treaty has had rules for the disposal of chicken and turkey carcases for a long time to prevent the introduction of Newcastle Disease into penguins but there are many other potential diseases that we have little information about. Work on animal diseases continues to attract little interest or funding in most National Programmes (except Australia) making it likely that we will not be prepared when a major outbreak occurs.

There are several common features in all of this. The first is the responsibilities of the National Antarctic Programmes for better control of the principal routes for introductions. For the most part it seems as though National Operators have either seen their cargo activities as low risk or been unwilling or unable to prioritize rigorous controls on packing and shipping. The second is the individual responsibilities of those going to the Antarctic, either as part of National Programmes or as tourists. The IPY sampling programme showed just how many and diverse were the propagules inadvertently trapped in clothing and in the treads of boots, never mind recognizing that visitors may be deliberately bringing seeds to sow. What we now need is the rest of the research on these problems, consistent control and quarantine policies and the resources required to eradicate material still in the early stages of colonization.

There are major efforts on South Georgia, Kerguelen and Macquarie to control introduced vertebrates but there is a continuing problem with funding environmental management and research as in many countries applied Antarctic research is not seen as competitive science. Something needs to change. If the science funding agencies will almost certainly reject most of the applied science proposals as not exciting enough, despite the consequences, perhaps COMNAP members could take a lead to try and initiate the science needed for future management before it is too late and in the meantime agree to use more effective cargo controls based on the evidence we have?

DAVID WaLton 